\title{
Large-eddy simulation of methane direct injection using the full injector geometry
}

\author{
M. R. Yosri ${ }^{\mathrm{a}, *}$, J. Z. Ho ${ }^{\mathrm{a}}$, M. Meulemans ${ }^{\mathrm{a}}$, M. Talei ${ }^{\mathrm{a}}$, R. L. Gordon ${ }^{\mathrm{a}}$, \\ M. J. Brear ${ }^{\mathrm{a}}$, D. Cosby ${ }^{\mathrm{b}}$, J. S. Lacey ${ }^{\mathrm{c}}$ \\ ${ }^{a}$ Department of Mechanical Engineering, University of Melbourne, Parkville, VIC 3010, \\ Australia \\ ${ }^{b}$ Continental Automotive Systems, Inc., Auburn Hills, MI, USA \\ ${ }^{c}$ Department of Mechanical Engineering, KU Leuven, 3001 Leuven, Belgium
}

\begin{abstract}
Understanding the mixing process of under-expanded gaseous-fuel jets from an outward opening injector is essential for developing Direct Injection (DI) internal combustion engines. This paper presents a Large-Eddy Simulation (LES) study of the DI of methane into a Constant Volume Chamber (CVC), considering the full, internal geometry of a prototype injector. Four cases at conditions relevant to Compressed Natural Gas (CNG) DI engines are investigated, with methane as a surrogate for CNG. A new post-processing method permits the 3D LES field to be projected into a $2 \mathrm{D}$ density gradient field that can be compared to a schlieren image. The LES results are then validated against high-speed, schlieren imaging experiments, demonstrating that the simulations are able to reproduce experimental trends. Three main regions of the external flow are observed: a recirculation zone just downstream of the injector tip, a stagnation zone and a far-mixing zone. The location of the stagnation zone increases as the CVC pressure decreases, consistent with a theory presented in the literature. The modelling of the full internal geometry of the injector leads to a determination of the injector pressure losses. Once the pressure loss within the injector is considered, a short version of the injector can reasonably represent the full injector for prediction of the external flow.
\end{abstract}

\footnotetext{
${ }^{*}$ Corresponding author

Email address: mysori@student.unimelb.edu.au (M. R. Yosri)
}

Preprint submitted to Fuel

August 17, 2020 
Keywords: Large-Eddy Simulation (LES), Constant Volume Chamber (CVC), Schlieren, Under-Expanded Gaseous Jet, Direct Injection (DI)

\section{Introduction}

Internal Combustion (IC) engines dominate the transport sector. One pathway to reduce their emissions is through the use of low carbon, alternative fuels such as Compressed Natural Gas (CNG). This fuel has significant potential as a long-term solution because of its favourable properties when compared to conventional fuels, including low Particulate Matter $(\mathrm{PM})$, nitrogen oxide $\left(N O_{x}\right)$, and $\mathrm{CO}_{2}$ emissions, and high antiknock resistance [1]. An in-depth understanding of CNG injection processes is required in order to optimise fuel mass flow and air/fuel mixing to obtain these benefits.

The most common fuel injection methods for natural gas Spark Ignition (SI) engines are Port Fuel Injection (PFI) and Direct Injection (DI). In Port Fuel Injection, CNG and air are mixed before entering the cylinder, whereas for Direct Injection CNG is injected directly into the cylinder. CNG DI leads to higher volumetric efficiency and power output than PFI for a given engine 15 displacement [5] 7]. To achieve sufficient mass flow rate and fast air/fuel mixing, CNG DI requires higher rail pressures [8], typically from 16 to 20 bar compared to 2 to 10 bar for PFI [9, 10.

In the DI system, the Nozzle Pressure Ratio (NPR) is defined as the ratio of rail pressure to cylinder or chamber pressure. The NPR is one of the critical parameters affecting the fuel mass flow rate and air/fuel mixing. Donaldson and Snedeker showed that by increasing the NPR, the gas jet transitions from a subsonic jet to moderately under-expanded $(1.1<N P R<2)$ and eventually to a highly under-expanded jet $(2<N P R)$ [11. With DI rail pressures of 20 bar and chamber pressures from 0.4-4 bar at the start of the injection, moderately to highly under-expanded jets are expected to be present in CNG DI. These jets display complex flow phenomena such as shock waves and expansion fans which affect the mass flow rate and air/fuel mixing [12]. 
In addition to NPR, the geometrical features of the gas injector can have an impact on the mass flow rate and air/fuel mixing. Early generations of CNG direct injectors had a similar design to gasoline direct injectors, featuring an inward opening valve. This kind of gas injector suffers from issues such as fuel leakage. The newest generation of CNG direct injectors feature an outward opening poppet valve which can be sealed by the cylinder pressure [13. However, the geometry of outward opening injectors is complex. Phenomena such as choking, shock waves and boundary layer separation can occur as compressible gas flows through the small passages [14].

Swanteka et al. investigated the quasi-steady-state behaviour of CNG DI by varying the fuel rail pressure from 10 bar to 15 bar [15. They showed that for an outward opening injector, the external flow could be divided into 40 recirculation, stagnation, and mixing regions. Keskinen et al. showed that the shape of the jet of the outward-opening injector is strongly affected by changes of the injection timing, NPR, and the protrusion angle of the injector's poppet valve [16. Vuorinen et al. and Hamzehloo et al. carried out LES to investigate the transient development of highly under-expanded gaseous jets of methane

$45\left(\mathrm{CH}_{4}\right)$, nitrogen $\left(\mathrm{N}_{2}\right)$ and hydrogen $\left(\mathrm{H}_{2}\right)$ in a wall-bounded closed system with a single hole nozzle [12, 17 20]. They showed that increasing NPR can increase the Mach disk location and width, the penetration length and the volumetric growth of the jet. They also found that increasing the chamber temperature at a given NPR results in an increase of both the jet penetration and volume.

50 A comprehensive transient simulation of CNG DI through a realistic injector geometry has not yet been reported.

One key parameter in the modelling of these types of injectors is considering the valve lift at the start of injection. Baratta et al. compared the jet shape of the CNG DI qualitatively with schlieren images with and without considering 55 the needle valve movement [21 23]. They showed that the movement of the injector's needle valve causes pressure waves to propagate within the injector, affecting the injector mass flow rate. Deshmukh et al. used LES to study the transient development of an outward opening injector in an open ambient con- 
dition without considering the poppet valve motion [14, 24, 25]. The transient injector movement was shown to have a significant impact on the gaseous jet formation and air/fuel mixing parameters such as penetration length, maximum width and volumetric growth of the jet. Up to $30 \%$ over-prediction compared with experimental results can be observed if the valve lift movement is not considered.

This study therefore undertakes LES of methane direct injection with simulation of the full internal geometry and valve lift of an outward opening, prototype injector. The simulation results are compared with experimental results from a Constant Volume Chamber (CVC) [26]. Different conditions are considered by varying the chamber pressure and temperature. The flow field inside the

70 injector and the external jet characteristics are studied in detail to determine the requirements for high-fidelity simulation of CNG injection.

\section{Experimental setup}

\subsection{CNG injector}

The injection hardware is a prototype DI CNG injector provided by Conti-

75 nental [27]. A cross-section of this injector is shown in Figure 1. It consists of two main sections, which are intended to reduce gas leakage. There is an internal, inward opening "cold" valve that is actuated by a solenoid, and an outward opening "hot" valve that is spring actuated and is driven by the gas pressure force. The gas delivered by this injector is in a hollow cone configuration with a $8050^{\circ}$ angle poppet valve. The cold valve has an asymmetric geometry, with two holes downstream of the valve whose axes are in the y-direction.

\subsection{Constant Volume Chamber (CVC) and operating conditions}

The Constant Volume Chamber (CVC) was recently used in a series of experimental studies performed by the group [26, 28, 31]. The CVC is a stainless steel cube with the intersection of three $90 \mathrm{~mm}$ diameter holes and fused silica windows, providing optical access to the chamber. 


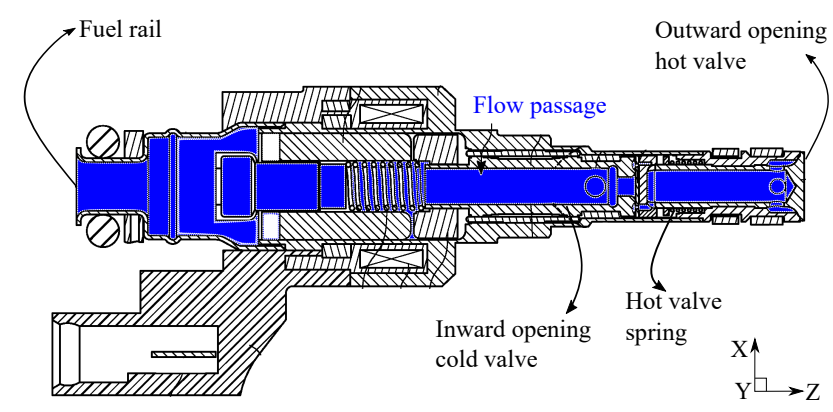

Figure 1: Sectional view of the prototype Continental DI CNG injector, indicating the flow passage in blue, and the inward ("hot") and outward opening ("cold") valves [27].

In the study by Lacey et al., methane (a surrogate for CNG) was injected into quiescent, non-reacting nitrogen to examine the fundamental mechanisms governing the development of methane jets [26]. They investigated several thermodynamic states relevant to modern DI engines by varying the CVC temperature and pressure, and the fuel temperature. The two temperatures are intended to emulate a cold engine at $298 \mathrm{~K}$, and a fully warmed up engine at $360 \mathrm{~K}$. The pressures used in their study represent a range of in-cylinder pressures that the fuel jet could encounter, based upon different levels of boosting or different in95 jection timings. The rail pressure was kept constant at $20 \mathrm{bar}$, as this value is relevant to what would be expected in DI CNG engines. The experimental and numerical test conditions, shown in Table 1. will be investigated in this work.

Table 1: Operating conditions of cases considered.

\begin{tabular}{|c|c|c|c|}
\hline Case No. & Condition & CVC Pressure & CVC Temperature \\
\hline 1 & \multirow{3}{*}{$\begin{array}{c}\text { Changing } \\
\text { CVC Pressure }\end{array}$} & 0.4 bar & $298 \mathrm{~K}$ \\
\cline { 3 - 4 } & & 1 bar & $298 \mathrm{~K}$ \\
\hline 3 & & 3 bar & $298 \mathrm{~K}$ \\
\hline 4 & Changing Temperature & 1 bar & $360 \mathrm{~K}$ \\
\hline
\end{tabular}




\subsection{Valve lift profile}

The valve lift profile is required as a boundary condition in the LES injection

100

a Photron SA1.1 Fastcam and a $150 \mathrm{~mm}$ focal length macro lens to obtain this profile for different CVC conditions. The injector was pulsed for $2 \mathrm{~ms}$ and movies were recorded at 30,000 frame per second (fps) with a physical scaling of approximately $25 \mu \mathrm{m}$ per pixel. The edge of the poppet valve is determined in each image through a post-processing routine, and valve lift profile versus time can then be determined.

The valve lift profiles are shown for two cases in Figure 2. There is a 700 $\mu s$ delay between sending the "open" signal to the solenoid and the opening of the valve. The valve opens over approximately $300 \mu s$ until it reaches its maximum height. The injector's hot, inward opening valve then fluctuates until it reaches a stable condition after approximately a further $500 \mu \mathrm{s}$. When the signal is turned off, the valve gradually closes and experiences a bounce before completely closing. There are small differences between the valve lift profiles across the range of tested chamber pressures $\left(P_{C V C}\right)$. With increasing chamber

pressure, the amplitude and duration of the fluctuations increases. This may affect the injector mass flow rate, particularly for the case with the highest chamber pressure.

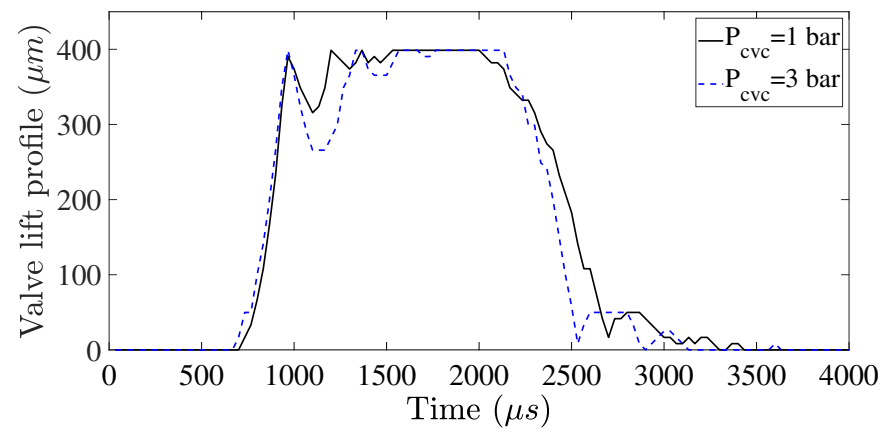

Figure 2: Experimental valve lift profile for $P_{C V C}=1$ bar (solid black line) and $P_{C V C}=3$ bar (dashed blue line) with $P_{\text {rail }}=20$ bar. 


\subsection{Validation mass flow rate measurement}

Validation data for the mass flow rate through the injector was obtained by measuring a long-duration static mass flow rate of a nitrogen injection into air at ambient conditions. The rail pressure was kept constant at 20 bar by using a bottle of pressurised nitrogen connected to a pressure regulator. The gas is then stored in an accumulator to provide enough gas during the time of injection. A Coriolis mass flow meter (Micro Motion CMF010M) was used to measure the mass flow rate, and a pressure transducer was installed before the injector to record the pressure during the injection. The injector was pulsed for 1 second to ensure the Coriolis mass flow meter could record a steady-state measurement. At each tested condition, the injection event was repeated five times to ensure the data were repeatable. The results of this experiment will be discussed in section 4.1

\section{Numerical methods}

LES was performed using the CONVERGE CFD software package 32. CONVERGE uses a finite volume method to discretise the conservation equations with a second-order-accurate spatial discretisation scheme. The Pressure Implicit with the Splitting of Operators (PISO) algorithm was then used to solve the governing equations 33. Shock treatment was undertaken with a step flux limiter 32. A variable time step, calculated based on the maximum of the Courant Friedrich Lewy (CFL) number was used. The time step varied from $1 e^{-9} s$ to $5 e^{-8} s$ with the total injection duration of $2 \mathrm{~ms}$.

\subsection{Governing equations}

LES decomposition is based on spatial filtering, accomplished by Favre density-weighted filtering, defined as:

$$
\widetilde{\phi}(\mathbf{x}, t)=\frac{\overline{\rho \phi}}{\bar{\rho}} .
$$


The quantity $\phi$ can then be decomposed into its filtered and sub-grid terms:

$$
\phi=\widetilde{\phi}+\phi^{\prime},
$$

where $\widetilde{\phi}$ is the filtered (or resolved) variable and $\phi^{\prime}$ is the Sub-Grid Scale (SGS) variable. The momentum equation is used here to explain the LES decomposition:

$$
\frac{\partial \bar{\rho} \widetilde{u_{i}}}{\partial t}+\frac{\partial \bar{\rho} \widetilde{u_{i}} \widetilde{u_{j}}}{\partial x_{j}}=-\frac{\partial \bar{P}}{\partial x_{i}}+\frac{\partial \overline{\sigma_{i j}}}{\partial x_{j}}-\frac{\bar{\rho} \partial \tau_{i j}}{\partial x_{j}}
$$

where $\rho$ is the density of the mixture, $u$ is the velocity, $P$ denotes the pressure and $\sigma_{i j}$ is the resolved shear stress tensor. The sub-grid stress term $\left(\tau_{i j}\right)$ is as follows:

$$
\tau_{i j}=\left(\widetilde{u_{i} u_{j}}-\widetilde{u_{i}} \widetilde{u_{j}}\right)
$$

The term $\tau_{i j}$ cannot be computed directly and needs to be modelled. The one equation, non-viscosity based Dynamic Structure model was used to model $\tau_{i j}$ [34. In this method, a transport equation for the sub-grid kinetic energy is additionally solved,

$$
\frac{\partial \bar{\rho} k}{\partial t}+\frac{\partial \bar{\rho} \widetilde{u_{j}} k}{\partial x_{j}}=\frac{\partial\left(\frac{\mu}{P r_{s g s}} \frac{\partial k}{\partial x_{j}}\right)}{\partial x_{j}}+\bar{\rho} \tau_{i j} \overline{S_{i j}}-\bar{\rho} \epsilon
$$

where $\operatorname{Pr}_{\text {sgs }}$ is set to be 0.87 and $\mu$ is the dynamic viscosity [34]. The term $\overline{S_{i j}}$

denotes the filtered strain rate tensor, $k$ is the sub-grid kinetic energy and $\epsilon$ is the sub-grid dissipation rate, defined as follows, respectively:

$$
\begin{gathered}
\overline{S_{i j}}=\frac{1}{2}\left(\frac{\partial \widetilde{u_{i}}}{\partial x_{j}}+\frac{\partial \widetilde{u_{j}}}{\partial x_{i}}\right), \\
k=\frac{1}{2}\left(\widetilde{u_{i} u_{i}}-\widetilde{u_{i}} \widetilde{u_{i}}\right), \text { and } \\
\epsilon=C_{\epsilon} \frac{k^{1.5}}{\Delta} .
\end{gathered}
$$


The variable $C_{\epsilon}$ is a model constant and $\Delta$ is the grid size. In this study, $C_{\epsilon}=1$ following the approach of [35].

Dynamic LES models require a second filtering operation using a test filter, ${ }_{160}$ which is twice the grid size $(\widehat{\Delta})$. The test level filtered stress tensor, $T_{i j}$ is defined as:

$$
T_{i j}=\left(\widehat{\widehat{u_{i} u_{j}}}-\widehat{\widetilde{u_{i}}} \widehat{\widetilde{u_{j}}}\right)
$$

Germano's identity [36] relates the grid level tensor to the test level tensor by:

$$
L_{i j}=T_{i j}-\widehat{\tau_{i j}}=\left(\widetilde{\widetilde{u_{i}}} \widetilde{u_{j}}-\widetilde{\widetilde{u}_{i}} \widetilde{\widetilde{u_{j}}}\right) \text {, }
$$

where $L_{i j}$ is the Leonard stress term [36]. In the dynamic structure model, the SGS stress tensor is modelled as a function of SGS kinetic energy which are given by:

$$
\begin{gathered}
\tau_{i j}=c_{i j} k, \\
T_{i j}=c_{i j} K,
\end{gathered}
$$

where $c_{i j}$ is the coefficient tensor and $K$ denotes the test level kinetic energy which is defined by:

$$
K=\frac{1}{2}\left(\widehat{\widetilde{u_{i} u_{i}}}-\widetilde{\mathrm{u}_{i}} \widehat{\widetilde{u_{i}}}\right) \text {. }
$$

The trace of the Leonard term relates the test and grid level kinetic energies by:

$$
K=\widehat{k}+\frac{1}{2} L_{i i} .
$$

Using equations 14 11 and 12, Germano's identity (Equation 10) can be written 170 as:

$$
L_{i j}=\frac{1}{2} c_{i j} L_{i i}
$$


The tensor coefficient $c_{i j}$ can now be obtained from Equation 15 and be substituted into Equation 11 to calculate $\tau_{i j}$ :

$$
\tau_{i j}=2 k \frac{L_{i j}}{L_{i i}},
$$

\subsection{Computational domain and grid parameters}

Figure 3 shows the computational domain, including the internal geometry of the injector, a portion of the CVC, and the boundary conditions. In order to reduce the computational cost, Adaptive Mesh Refinement (AMR) was employed [32]. AMR was activated based on thresholds on velocity and methane mass fraction $\left(\mathrm{Y}_{\mathrm{CH}_{4}}\right)$ fields. The base grid-size of this study is $1 \mathrm{~mm}$, and the smallest grid size is $0.03 \mathrm{~mm}$. Further details on the AMR algorithm can be found in Ref [32]. The minimum grid size was chosen follwoing Baratta et al., who propose that to obtain an accurate mass flow rate, the critical section of the injector should have at least 10-15 grid points [22]. In this geometry, this location is taken to be the throat at the choking location, which has 12 grid points. Moreover, for Case 1 (highest NPR), a simulation with a finer grid was performed, which resulted in negligible difference (5-7\%) compared to the penetration and cone angle results achieved with the original grid.

\subsection{Boundary Conditions}

A fuel rail pressure of $20 \mathrm{bar}$, methane mass fraction of 1 and temperature of $298 \mathrm{~K}$ or $360 \mathrm{~K}$ were used as the inlet condition. Depending on the operating regime, different wall boundary conditions can be used. The maximum Knudsen number was less than 0.1 for this injector, therefore the velocity slip boundary condition was applied to the walls, as proposed by [37. At the tip of the poppet wall, as the boundary layer separation is essential, the no-slip boundary condition was applied [14. All walls were adiabatic.

\subsection{Initial Conditions}

The initial conditions were imposed in three different regions. The flow path in the cold valve was initialised using the conditions at the injector inlet. As 


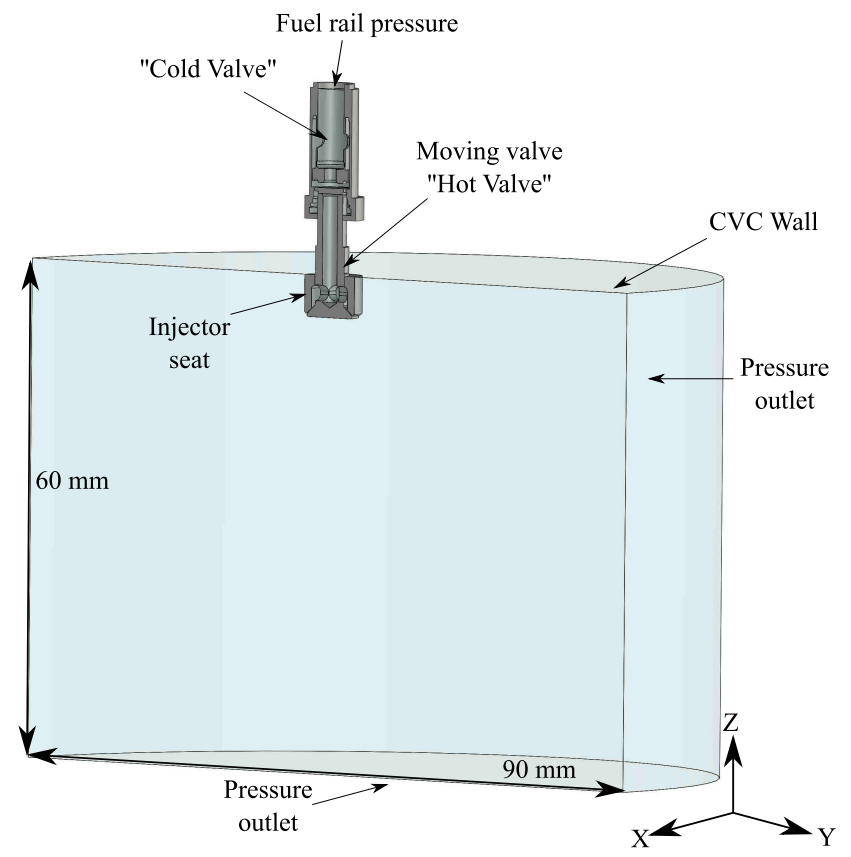

Figure 3: Sectional view of the computational domain.

it takes more than $500 \mu s$ to completely close the injector after the closing of the cold valve (see Figure 2), the flow path in the hot valve was initialised with the pressure and temperature of the CVC, but with a mass fraction of methane, $Y_{C_{4}}=1$. The third region is the chamber itself, which is initialised with the pressure and temperature of the selected case and pure nitrogen as a mass fraction $Y_{N_{2}}=1$.

\subsection{Post-processing method}

\subsubsection{Numerical representation of schlieren images}

Lacey et al. reported the results for the axial penetration of the jet and the jet spreading angle, which is defined as the cone angle $5 \mathrm{~mm}$ downstream of the injector [26]. These two values characterise the jet development. The axial penetration was recorded for $500 \mu s$ After the Start Of Injection (ASOI), where the fuel exits from the injector (0 ASOI $\mu s \approx 700 \mu s$ in Fig 2$)$ up until the jet leaves the imaging window at $37 \mathrm{~mm}$. The cone angle is calculated from $500 \mu \mathrm{s}$ 
to $2000 \mu \mathrm{s}$ ASOI, which is the period when the jet operates in a quasi-steady state condition.

To find these two parameters from the LES results, a new post-processing technique is required. The experimental schlieren images visualise the volumetric inhomogeneities in the gas by showing the variations in the refractive index projected onto a two-dimensional plane. The two-dimensional schlieren images are a set of lighter and darker regions representing the positive and negative density gradients in the direction normal to the knife-edge 38. The z-type schlieren imaging configuration used in Lacey et al. images the projected density gradient corresponding to the z-direction in the computational domain. In order to find the density gradient from the LES results, the three-dimensional data must first be projected onto the same two-dimensional plane as the focal plane of the schlieren imaging system. A post-processing code was written to approximate the density gradient in each grid point as:

$$
\frac{\partial \rho}{\partial x_{i}}=\frac{\rho_{x_{i}+d}-\rho_{x_{i}}}{d}
$$

where $\rho$ is the density, $x_{i}$ is the Cartesian coordinates and $d$ denotes the mesh size. The values on the original grid were linearly interpolated onto a grid of uniform spacing to determine the density gradients because AMR was used to generate the original grid. The linear Delaunay triangulation method was employed for this interpolation [39. The density gradient values were then spatially ensemble-averaged in the y-direction with a number of planes. The distance between each two planes, $\Delta$, was equal to the smallest grid size.

\subsubsection{Cone angle and penetration length}

The projected density gradient field was analysed to determine the jet bound235 ary, so that the cone angle and penetration length could be determined. A fluid element with a density gradient greater than $0.1 \%$ of the maximum value in the domain was considered to be inside the jet, provided that the mass fraction of methane is also greater than $0.1 \%$. These threshold values were found appropriate based on visual inspection of the jet, and conditioning with the fuel mass 
fraction avoids identification of density gradients from pressure waves.

\section{Results and discussions}

Validation results are presented for the injector mass flow rate, penetration length, jet spreading angle and location of the Mach disk using both experimental results and empirical correlations for all cases. Then, for Case $2\left(P_{C V C}=1\right.$ bar and $\mathrm{T}=298 \mathrm{~K})$ as a reference case, the flow within the injector and its effect on the external flow features such as penetration length and jet spreading angle is investigated. Finally, for Case 2, the transient development of the external flow and the mixing process is discussed.

\subsection{Injector mass flow rate}

The injector mass flow rate under steady state conditions was measured experimentally in Subsection 2.4 and compared with those obtained from analytical and LES results. In this injector, the flow is choked when the downstream pressure (i.e. $P_{C V C}$ ) falls below a critical pressure, $P^{*}$, determined by:

$$
\frac{P^{*}}{P_{t}}=\left(\frac{2}{\gamma+1}\right)^{\frac{\gamma}{\gamma-1}}
$$

250

where $\gamma$ is the specific heat ratio of the gaseous jet and $p_{t}$ indicates the upstream static pressure (i.e. the fuel rail pressure). At a 20 bar fuel rail pressure, the value of $p^{*}$ is 10.56 bar for a nitrogen jet and 10.88 bar for a methane jet. The maximum CVC pressure is 3 bar in this study, hence the flow is choked for all cases. Therefore, the mass flow rate $(\dot{m})$ can be calculated using the following formula [0]:

$$
\dot{m}=\frac{P_{t}}{\sqrt{R T_{t}}} A^{*} \sqrt{\gamma}\left(1+\frac{\gamma-1}{2}\right)^{\frac{\gamma+1}{2(1-\gamma)}},
$$

where $T_{t}$ is the upstream static temperature $\left(T_{t}=298 \mathrm{~K}\right), R$ is the gas constant and $A^{*}$ is the choked cross-sectional area. The mass flow rate was calculated analytically using Equation 19, and numerically from the LES results. For the 
Table 2: The injector mass flow rate obtained from experimental, numerical and analytical results; $P_{\text {rail }}=20$ bar, $\mathrm{T}=298 \mathrm{~K}$

\begin{tabular}{|c|c|c|}
\hline Approach & Mass flow rate $(g / s)$ & Difference $\%$ \\
\hline Experiments & 11.07 & - \\
\hline Analytical & 11.38 & $2.8 \%$ \\
\hline Numerical & 10.57 & $4.5 \%$ \\
\hline
\end{tabular}

analytical solution, $A^{*}$ was determined from the LES results. These values are compared with the measured data in Table 2 .

The time-averaged steady-state Mach number field obtained from LES is shown in Figure 4 . In order to illustrate the choking area within the injector, the iso-surface of Mach =1 is used. The flow is choked inside the injector just upstream of the nozzle exit when the valve is fully open. As can be seen from Table 2 , both analytical and numerical results show a very good agreement (less than $5 \%$ difference) with the experimental data.

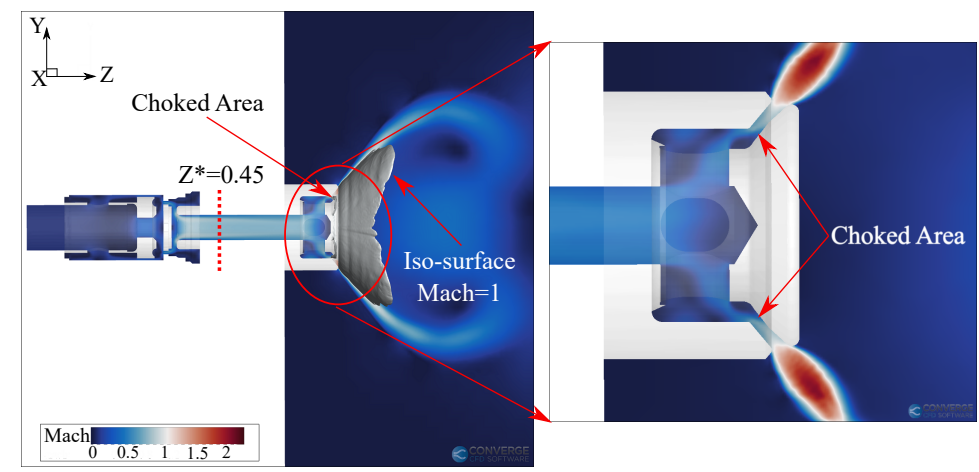

Figure 4: Time-averaged steady-state Mach field within the injector for nitrogen $P_{C V C}=1$ bar, Prail=20 bar and T=298 K, $Z^{*}$ is the non-dimensionalised injector length.

\subsection{Pressure loss inside the injector}

Figure 5 a shows the area-averaged pressure at various streamwise locations through the injector under quasi-steady state conditions (500 $\mu s$ to $2000 \mu s$ ASOI) for Case 2. A significant pressure loss within the injector is observed 
from 20 bar in the rail to 10 bar at the nozzle exit. The variable $Z^{*}$ is the axial distance from the injector inlet, non-dimensionalised by the total length (See Figure 4). Figure $5 \mathrm{~b}$ shows the area-averaged pressure at $Z^{*}=0.45$ obtained from the simulation of the entire injector under transient conditions. The pressure is initialised at $1 \mathrm{bar}$ and then increases to 12 bar at $300 \mu \mathrm{s}$. After that, it reaches a quasi-steady-state condition (see Figure 5b). The observed fluctuations are due to the pressure waves travelling inside the injector.

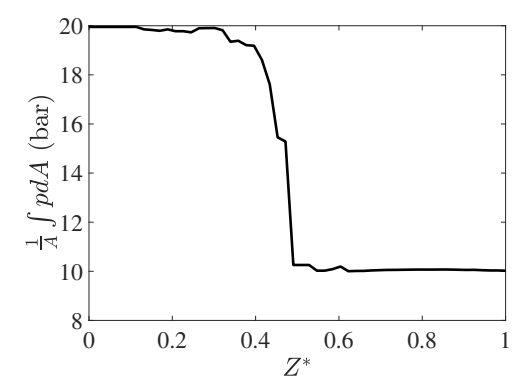

(a)

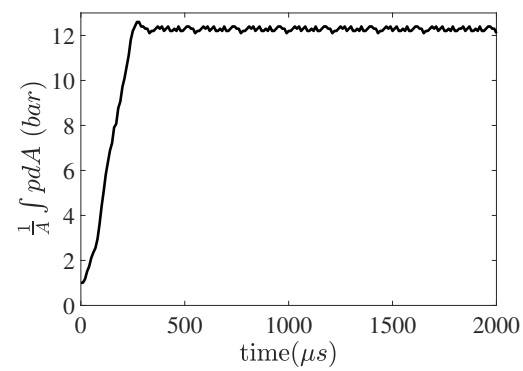

(b)

Figure 5: a) Area averaged pressure with respect to non-dimensionalised injector length $\left(Z^{*}\right)$, b) Area averaged pressure at $Z^{*}=0.45$ with respect to time $P_{C V C}=1$ bar, $\mathrm{T}=298 \mathrm{~K}$.

In order to investigate the impact of the injector internal geometry on global external flow parameters, a short version of the injector is modelled from $Z^{*}=$

0.45 for Case 2. Two additional simulations with input pressures of 20 and 12 bar and a CVC pressure of 1 bar are performed for comparison. Figure 6 shows the penetration length and the jet spreading angle for all simulations and the experimental results. When the full injector geometry is considered, a very good agreement with the experimental penetration length is achieved. For the short injector with the 20 bar input pressure, an over-prediction of at least $25 \%$ at each instant is observed for both the penetration length and cone angle. The penetration length for the 12 bar case shows a slight over-prediction (around $7 \%$ ) at the beginning of the injection. This is because the pressure in the hot valve is still below 12 bar before approximately $300 \mu \mathrm{s}$ ASOI. Once the injector

290 is fully open, the difference between the results with the full injector and the 


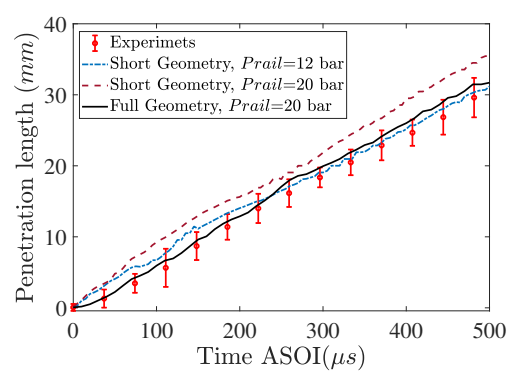

(a)

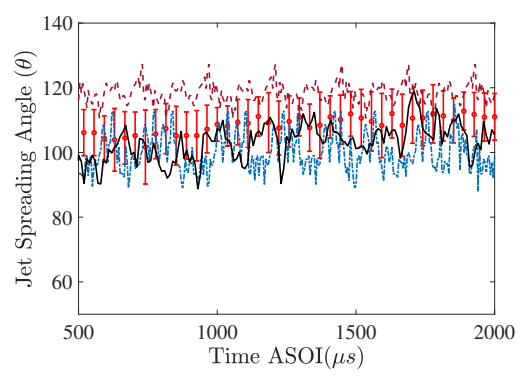

(b)

Figure 6: Experimental vs. numerical a) penetration length and b) jet spreading angle for the long and short injector with different rail pressure as labelled, $P_{C V C}=1, \mathrm{~T}=298 \mathrm{~K}$, methane.

short version is less than $5 \%$ for the penetration length. A better agreement between the results of the full injector and the short version is observed for the cone angle in this case.

\subsection{Injector internal flow}

Figure 7 illustrates the pressure and Mach development within the injector for different instants during injection for Case 2. At $5 \mu \mathrm{s}$, the gas from the cold valve at 20 bar is entering the hot valve at 1 bar. At $90 \mu s$, the PrandtlMeyer expansion fans can be observed just upstream of the hot valve. The total pressure in the hot valve increases to around 6 bar at $150 \mu \mathrm{s}$. The jet features diamond shape structures due to the reflection of compression waves from the walls and a formation of oblique shock waves [20. These structures are present up to the point that the flow reaches subsonic conditions. At later times up to $300 \mu s$, the supersonic region in the hot valve increases in length while the total pressure in the hot valve increases as well. After that, the boundary between the supersonic and subsonic regions retreats back as the pressure ratio between the hot and cold valves decreases. At $350 \mu \mathrm{s}$, this ratio is below two, and therefore the shock waves dissipate quickly within the injector. As demonstrated in Figure 6. neglecting these complex dynamics during the injection process can lead to inaccurate results at the early stages of injection. 


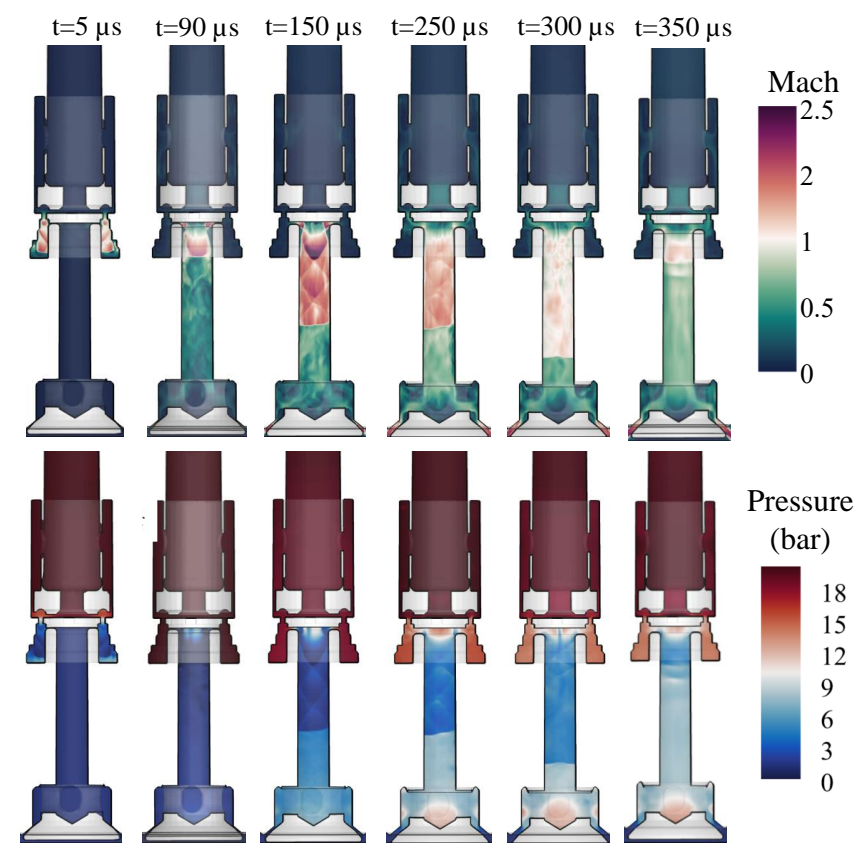

Figure 7: Mach and pressure fields within the injector at different instants as labelled, Case 2: $P_{C V C}=1$ bar, $\mathrm{T}=298 \mathrm{~K}$. 

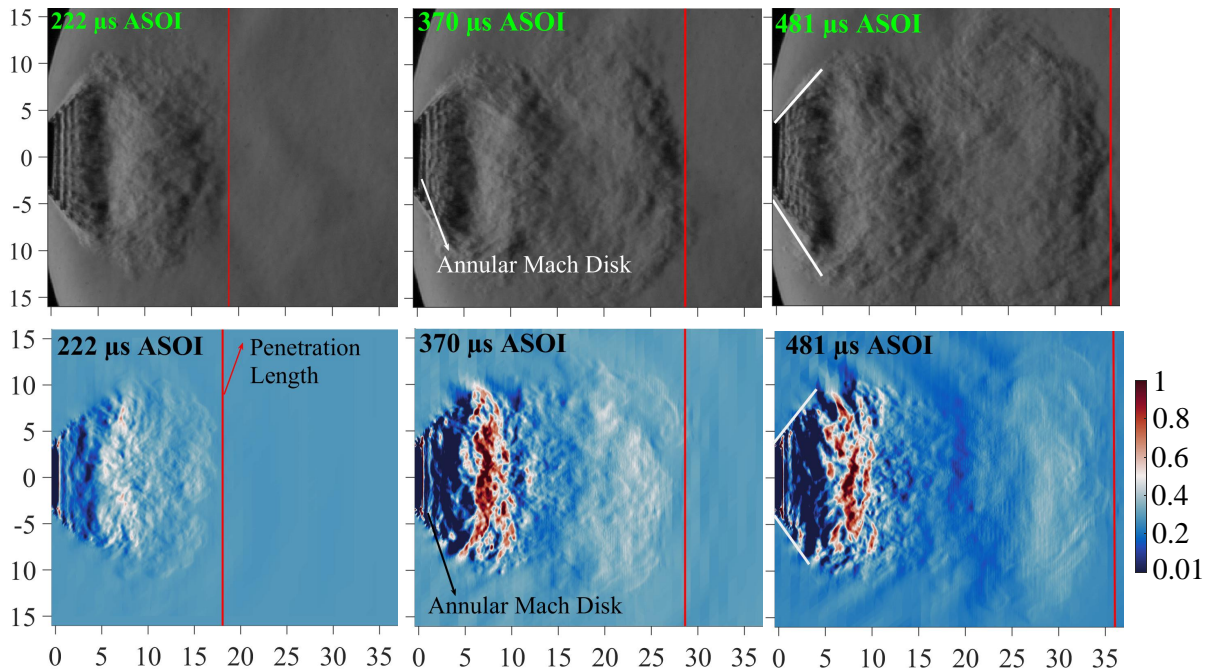

Figure 8: Instantaneous external flow features for Case 2 during the injection, shown with schlieren imaging (first row) and simulation results using the density gradient method (second row).

\subsection{Injector external flow}

\subsubsection{Comparison with experimental results}

Figure 8 shows a comparison between schlieren images and the LES results using the projected density gradient method (see Section 3.5.1) at different instants for Case 2. Jet features such as the penetration length and cone angle 315 are shown. Qualitatively, the experiments and simulations appear consistent. A region featuring high density gradients with shock structures such as Mach disks, shown as vertical lines, are present close to the poppet valve. Further downstream much smaller values of density gradients are observed.

Quantitative comparison between experimental and simulation results is performed using the Mach disk location, the penetration length and the cone angle. The Mach disk location, $H_{\text {disk }}$, the distance from the Mach disk to the nozzle exit, is presented in Table 3 for Cases 1,2 and 4 . Case 3 with $P_{C V C}=3$ bar has a lower NPR and is in the moderately under-expanded jet regime $(N P R=3.34<4.05)$, which does not feature a Mach disk. The variable ${ }_{325} H_{\text {disk }}$ can also be obtained empirically from the correlation proposed by Crist 
Table 3: Location of the Mach Disk.

\begin{tabular}{|l|c|c|c|c|}
\hline \multicolumn{1}{|c|}{ Case } & $\begin{array}{c}H_{\text {disk }} / D \\
\text { Numerical }\end{array}$ & $\begin{array}{c}H_{\text {disk }} / D \\
\text { Experiment }\end{array}$ & $\begin{array}{c}\text { Difference } \\
\text { to Experiment }\end{array}$ & $\begin{array}{c}\text { Difference } \\
\text { to Empirical } \\
\text { Correlation }\end{array}$ \\
\hline $\begin{array}{l}\text { 1) } P_{C V C}=0.4 \text { bar } \\
\mathrm{T}=298 \mathrm{~K}\end{array}$ & 3.05 & 3.15 & $4.12 \%$ & $2.00 \%$ \\
\hline $\begin{array}{l}\text { 2) } P_{C V C}=1 \text { bar } \\
\mathrm{T}=298 \mathrm{~K}\end{array}$ & 1.98 & 2.02 & $4.01 \%$ & $2.90 \%$ \\
\hline $\begin{array}{l}\text { 4) } P_{C V C}=1 \text { bar } \\
\mathrm{T}=360 \mathrm{~K}\end{array}$ & 2.06 & 2.15 & $4.87 \%$ & $8.01 \%$ \\
\hline
\end{tabular}

et al. [1]:

$$
H_{\text {disk }} / D_{e q}=0.67 \sqrt{N P R}
$$

where $D_{e q}$ denotes the equivalent diameter of the annulus flow pathway. The difference between $H_{d i s k} / D_{e q}$ obtained from the LES and experimental results is less than $5 \%$. The agreement with the empirical correlation is slightly higher for Case 4 with a higher CVC temperature.

The results for the jet spreading angle are compared with the experimental results in Figure 9. The jet spreading angle was measured $500 \mu \mathrm{s}$ ASOI when the jet had a sharp edge. An agreement to within $2 \%$ at each instant was observed for all cases.

Figure 10 shows the comparison between LES, experimental and analytical results for the penetration length. An updated version of the Hill and Ouellette correlation by Hajialimohammadi et al. was used to calculate the analytical penetration length [42, 43]. The analytical solution was developed for a single hole injector considering the conservation of momentum, and can be described 


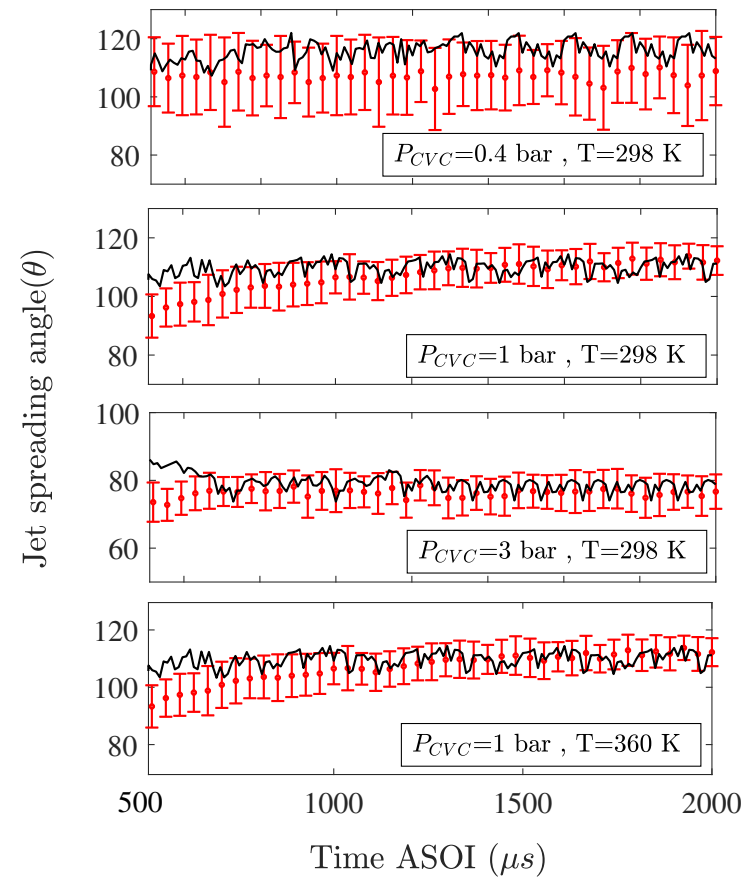

Figure 9: Experimental (circle) vs. numerical jet spreading angle (solid line) for case 1 to 4 as labelled. as:

$$
Z_{t}=\Gamma D_{e q}^{\frac{1}{2}}\left[\frac{\gamma_{a} \pi}{4} \frac{P_{e f f}}{P_{a}} R_{a} T_{a}\left(\frac{2}{\gamma_{a}+1}\right)^{\left(\frac{\gamma_{a}}{\gamma_{a}-1}\right)}\right]^{\frac{1}{4}} t^{\frac{1}{2}}
$$

where $Z_{t}$ is penetration length, $t$ denotes time, $\Gamma=3$ and the subscript " $a$ " corresponds to the ambient chamber pressure [42. The variable $P_{\text {eff }}$ is the effective pressure at the nozzle exit, which is less than the fuel rail pressure.

As shown in Fig 10, the analytical solution predicts much higher penetration at the early stages. This is not surprising given that this solution is developed for a fully open single hole injector. While there is a good agreement with the experimental results for Cases 2 and 4 with chamber pressure of 1 bar, the agreement is not as good for Cases 1 and 3 at $250 \mu \mathrm{s}$ ASOI.

Several factors contribute to this. For Case 1, with the highest NPR, the ex- 

are expected to be more sensitive to the geometrical features of the injector and boundary conditions for such a high NPR. Therefore, any small discrepancy is expected to have a large impact on the results. This is also observed in the level of uncertainty in the experimental results. For Case 3, although the bouncing the valve lift profile is an ensemble average, and the raw profiles show notable fluctuations.

Figure 11 shows the simulation results, highlighting the effect of changing the CVC pressure and temperature on the jet spreading angle. Increasing the

that the penetration length has a 0.8 power-law dependency with time after approximately $500 \mu \mathrm{s}$ ASOI [14, 44]. The constants $A_{1}$ to $A_{3}$ have an inverse relation with CVC pressure to the power of 0.25. Equation 21 also shows that $Z_{t} \propto 1 / P_{C V C}{ }^{0.25}$.

Collectively, the results of Figures 11 and 12 show that the penetration length and the cone angle both have an inverse relationship with the chamber pressure, and a direct relationship with temperature, consistent with the theoretical argument of Lacey et al. [26]. 

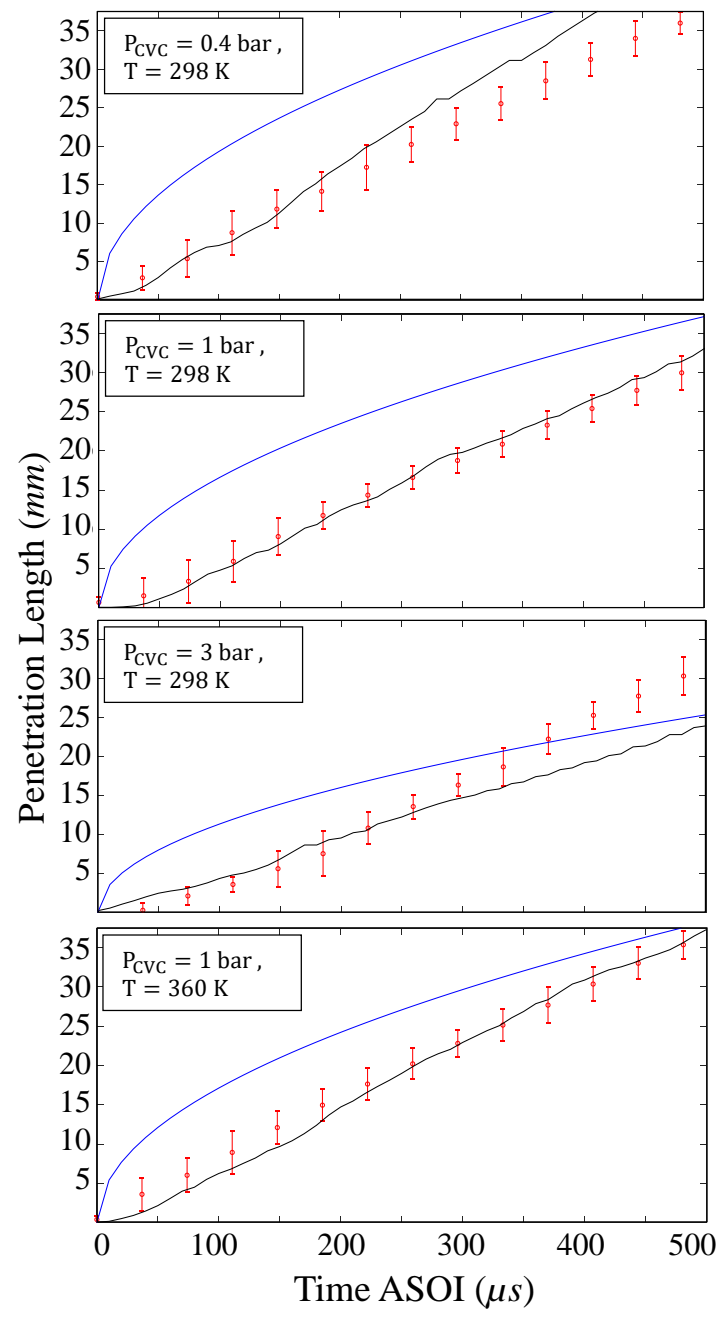

Figure 10: Experiment (red circle with error bars) compare with numerical (black solid line) and analytical penetration length (blue solid line) for Case 1 to 4 , top to bottom. 


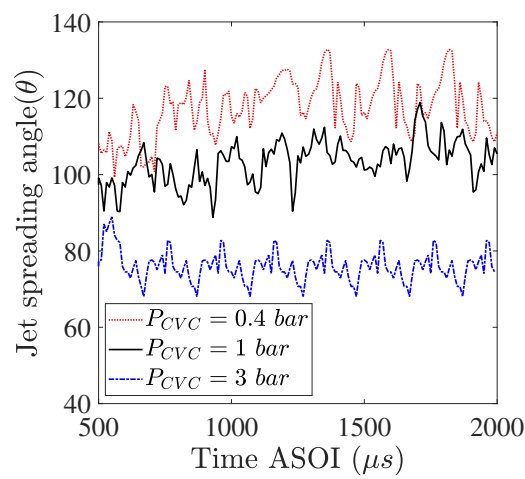

(a)

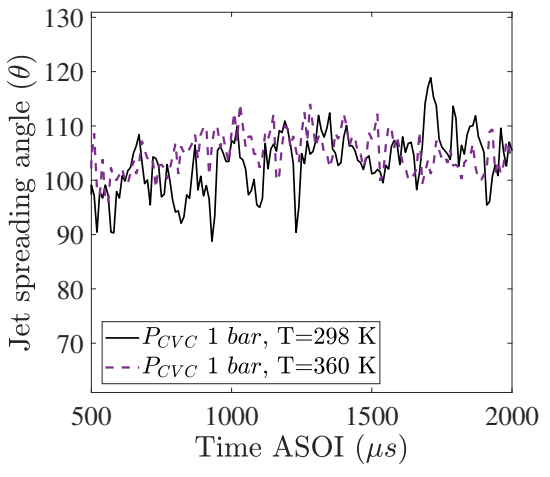

(b)

Figure 11: Numerical jet spreading angle for a) different CVC pressures b) different CVC temperatures as labelled.

\subsubsection{Analysis of the jet development}

1. $20 \mu \mathrm{s}$ ASOI, a three dimensional toroidal vortex ring initiates at the tip of the jet. It is not axisymmetric, due to asymmetric holes downstream of injector. At later times, as the hollow cone jet increases in size, it collapses into a single jet $(250 \mu s$ ASOI).

Figure 14 shows the transient development of the hollow-cone jet for the under-expanded jet $\left(P_{C V C}=1\right.$ bar $)$ in the $Y-Z$ plane. At the start of injection, boundary layer separation occurs as the flow passes over the poppet valve at the tip of the injector. The annular bow shock is formed close to the tip, and initial annular tip vortices at $20 \mu \mathrm{s}$ ASOI are observed. At later times, as the high-speed methane enters the CVC, the jet entrains the quiescent nitrogen, both from inside and outside the hollow cone. This causes the development of a low-pressure zone in front of the poppet valve. The tip vortices in the inner region grow in size, forming large scale eddies, impinging onto the poppet valve. This creates a recirculation zone, enhancing methane/nitrogen mixing. At $120 \mu s$ ASOI, the Mach disk is formed when the poppet valve is partially open. The presence of the Mach disk and shock cells region postpones mixing. 


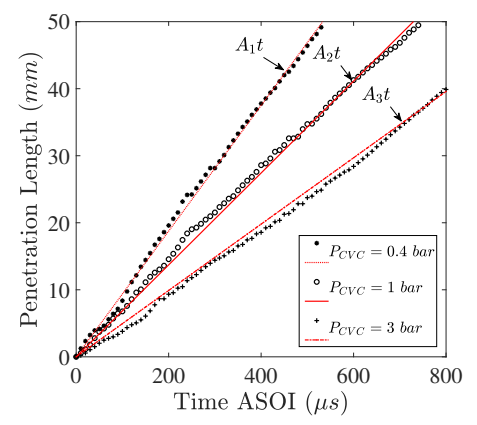

(a)

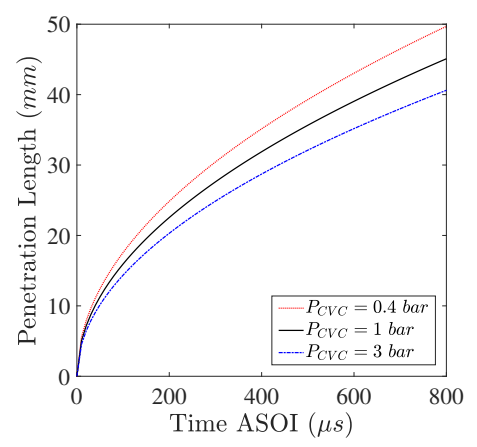

(c)

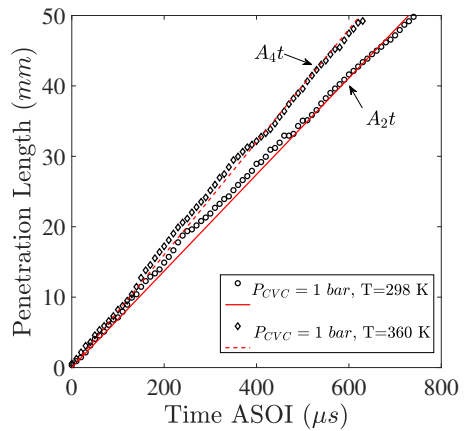

(b)

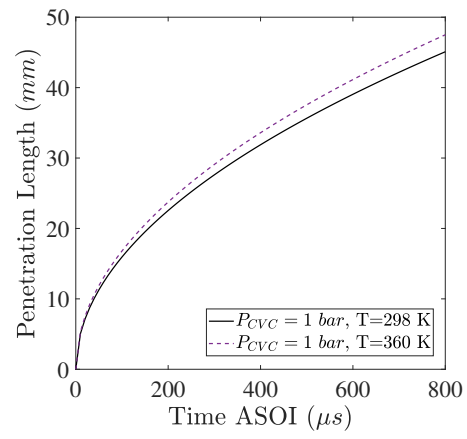

(d)

Figure 12: Jet penetration results of a) numerical at different CVC pressures b) numerical at different CVC temperatures c) analytical at different CVC pressures c) analytical at different CVC temperatures labelled. 


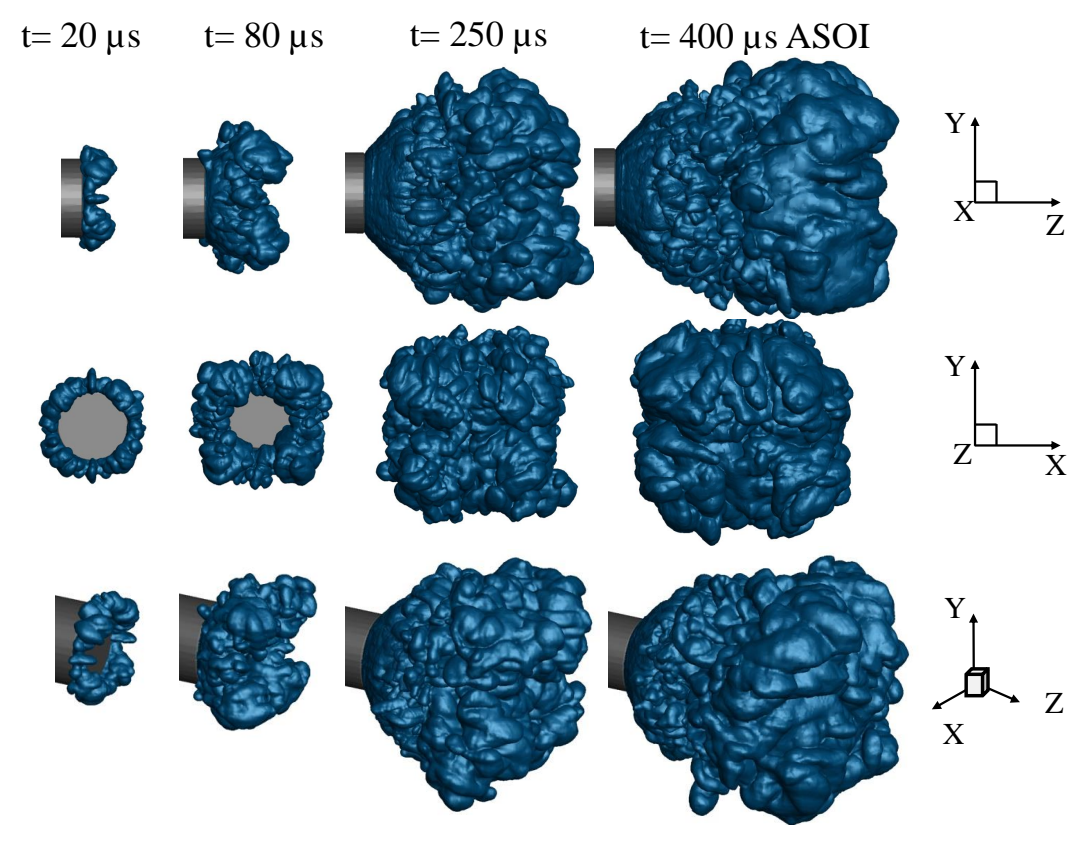

Figure 13: Iso-surface of $Y_{\mathrm{CH}_{4}}=0.01$ at different instants for Case 2

Downstream of these features, viscous forces become dominant and the shock cells region disappear [12]. By $350 \mu s$ ASOI, the hollow cone jet has collapsed into a single jet. A stagnation zone is formed downstream of the recirculation zones, and a far-mixing region is present, as seen at $450 \mu \mathrm{s}$ ASOI [15. At this time, the injector is fully open, with the far-mixing region featuring subsonic turbulent mixing.

Figure 15 shows a comparison between all cases in terms of the mean and standard deviation of the methane mass fraction under quasi-steady state conditions at the mid Y-Z plane of the jet. Both inner and outer mixing layers are formed downstream of the injector tip with their thickness increasing up to the point that they merge into a one mixing layer. After this point, high fluctuations of $Y_{\mathrm{CH}_{4}}$ are observed, consistent with the results presented in [14. The CVC pressure has an impact on the formation and the shape of these mixing 410 layers. By increasing the CVC pressure, the mixing layers merge closer to the nozzle exit. This is expected because when the CVC pressure is increased, the 


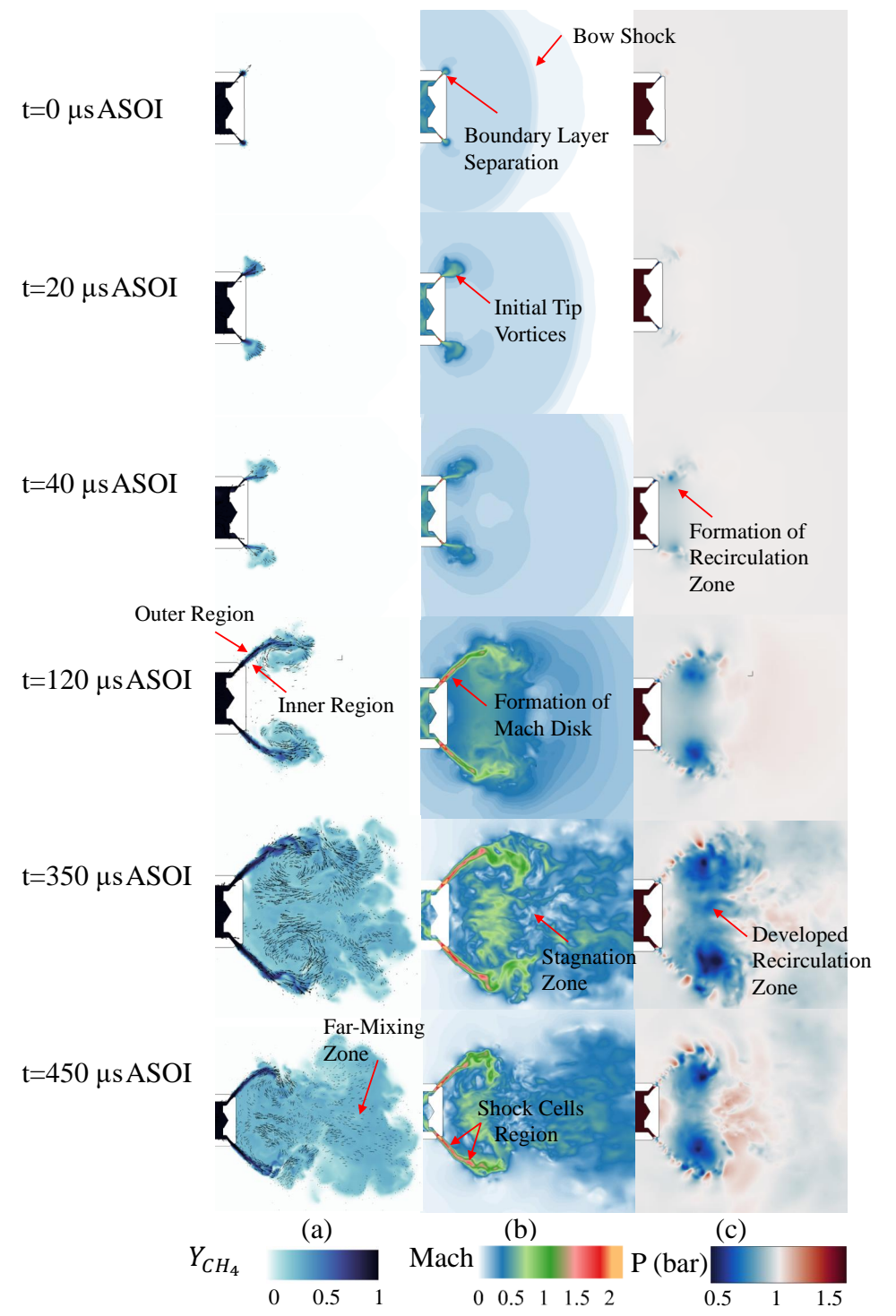

Figure 14: Transient development of the under-expanded jet (Case 2), shown using a) methane mass fraction field superimposed with velocity vectors b) Mach field and c) pressure field. 


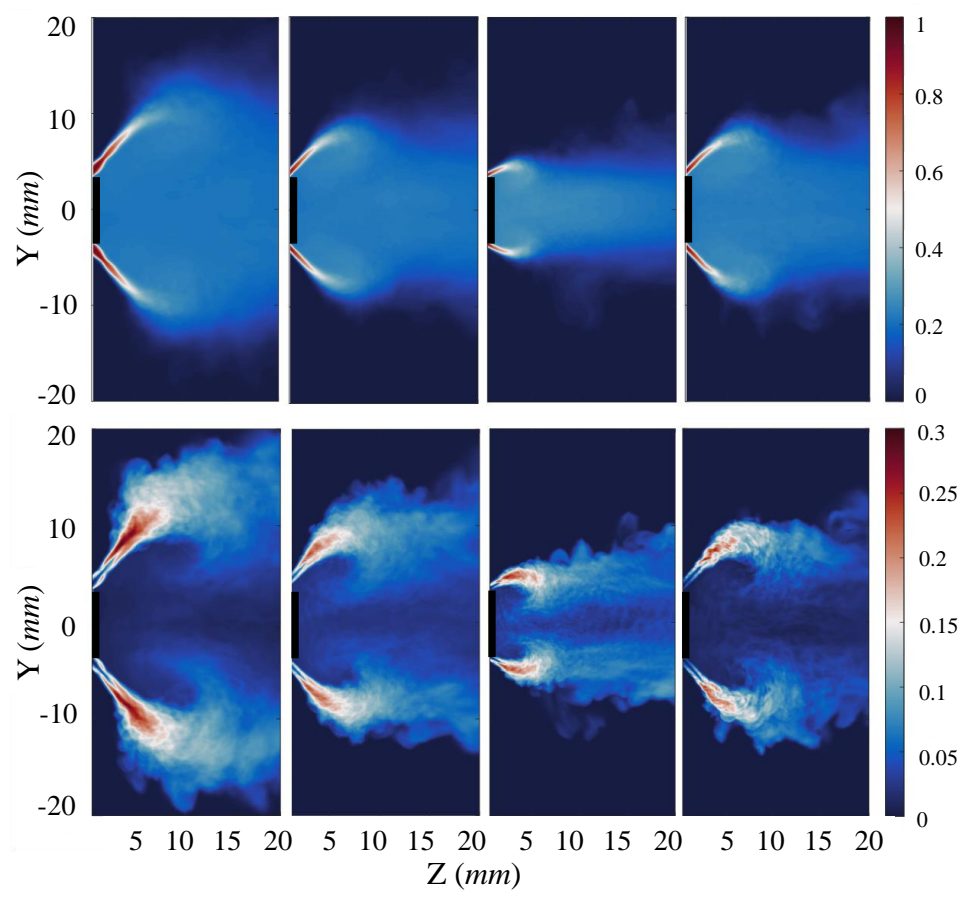

$\begin{array}{llll}\text { (a) Case } 1 & \text { (b) Case } 2 & \text { (c) Case } 3 & \text { (d) Case } 4\end{array}$

Figure 15: Mean (Top) and standard deviation (bottom) of the fuel mass fraction at the mid $Y-Z$ plane at quasi steady state condition (500 to $2000 \mu s)$, as labelled.

NPR is decreased and consequently, the shock affected region is reduced in size [12].

To further examine the jet development, Figure 16 shows the flow streamlines 415 and the field of $Y_{\mathrm{CH}_{4}}$ for different cases at $\mathrm{t}=600 \mu \mathrm{s} A S O I$ when the quasisteady state is reached. While the recirculation zone enhances mixing in the inner region, mixing dominantly occurs in the outer region for the far-mixing zone. The recirculation zone evidently increases in size as the CVC pressure decreases, pushing the far mixing zone further downstream.

Considering the stagnation point as the streamwise location on the jet axis at the which the streamwise velocity is zero, a recirculation zone length $\left(L_{R}\right)$ can be obtained. The mean value of $L_{R}$ is reported in Table 4 showing that the size of the recirculation zone is strongly dependant on the CVC pressure. 


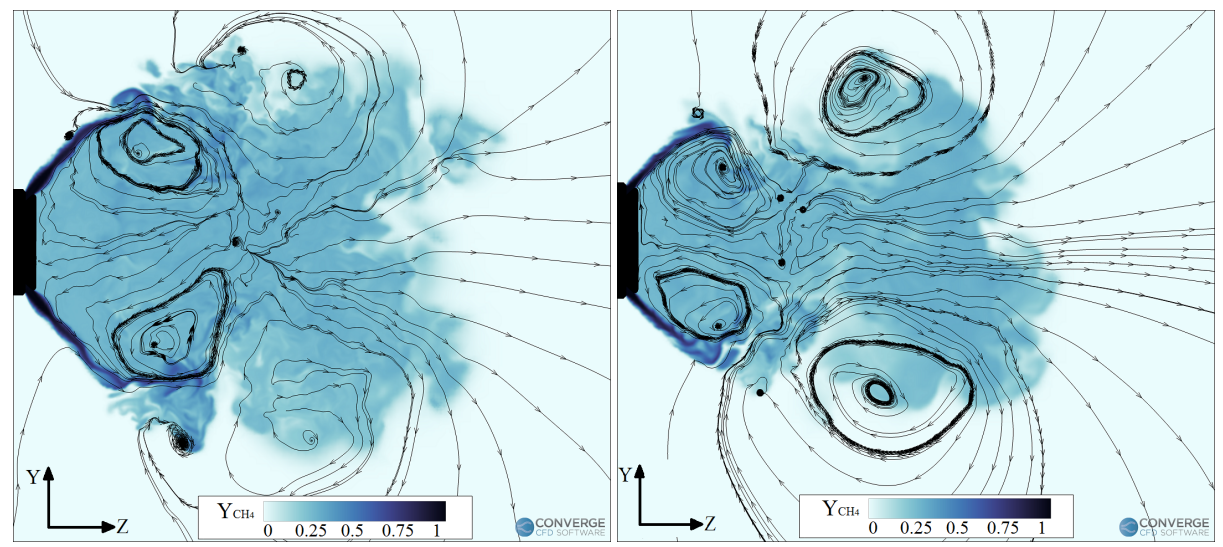

(a) Case 1

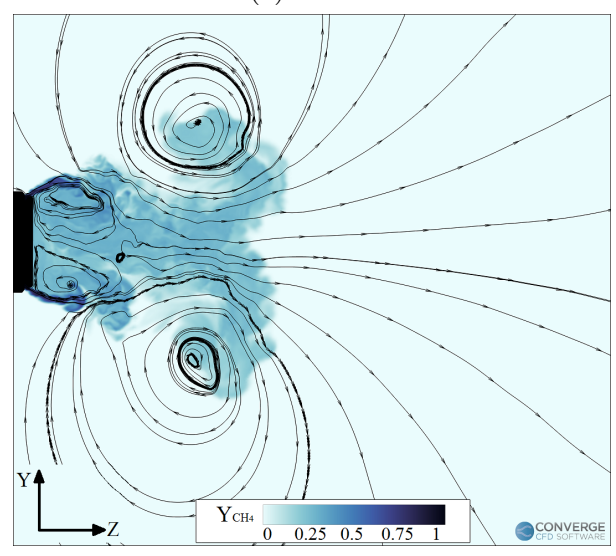

(c) Case 3 (b) Case 2

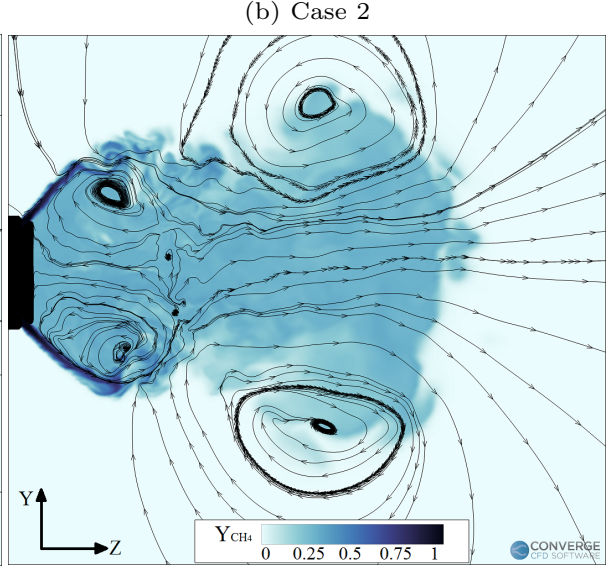

(d) Case 4

Figure 16: Stream plot of the velocity vector field for different cases superimposed on the mass fraction field, $500 \mu \mathrm{s}$ ASOI, as labelled. 
Table 4: Size of re-circulation zone $\left(L_{R}\right)$ for different cases.

\begin{tabular}{|c|c|c|c|}
\hline No. & $\begin{array}{c}\text { CVC pressure } \\
(\text { bar })\end{array}$ & $\begin{array}{c}\text { Temperature } \\
(\mathrm{K})\end{array}$ & $\begin{array}{c}\text { Mean size of } \\
\text { the re-circulation zone } L_{R}(\mathrm{~mm})\end{array}$ \\
\hline 1 & 0.4 & 298 & 18.39 \\
\hline 2 & 1 & 298 & 12.23 \\
\hline 3 & 3 & 298 & 6.94 \\
\hline 4 & 1 & 360 & 12.33 \\
\hline
\end{tabular}

Massey et al. developed a scaling law for the recirculation zone length behind the bluff body using the equation for the conservation of momentum [45. For a fixed geometry, this scaling can be written as follows:

$$
L_{R} \propto \frac{U_{b}}{P},
$$

where $U_{b}$ is the nozzle exit bulk velocity in the direction normal to the bluff body and $P$ is the chamber pressure. For our cases, the nozzle is choked and therefore the resulting velocity is constant. Therefore, Equation 23 can be rearranged as,

$$
L_{R} \propto \frac{\cos (\theta / 2)}{P}
$$

where $\theta$ is the spreading angle. Figure 17 shows that the scaling has a reasonable performance for the cases studied here. Once again, these results highlight the impact of the CVC pressure on the external flow dynamics.

\section{Conclusions}

Large-eddy simulations (LESs) of methane direct injection into a Constant Volume Chamber (CVC) considering the full internal geometry of a prototype, hollow-cone injector were performed. Three cases with different CVC pressures of 3,1 and 0.4 bar at $298 \mathrm{~K}$ were considered with fourth case featuring a gas and CVC temperature of $360 \mathrm{~K}$ with a CVC pressure of 1 bar. All cases had the same rail pressure of 20 bar. These conditions were all relevant to CNG DI engines considering different injection strategies. 


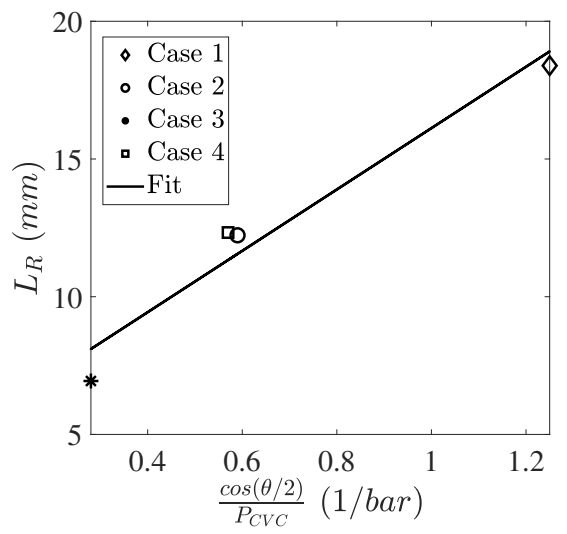

Figure 17: Variation of $L_{R}$ for different cases, markers are LES results and the trend-line as labelled.

The results were first validated against high-speed schlieren imaging from Lacey et al.'s experimental work using a new post-processing concept [26]. An excellent agreement for the jet spreading angle was achieved while a varying degree of agreement was observed for the jet penetration length. The jet penetration length showed an excellent agreement for the case with the CVC pressure of 1 bar while overprediction and underprediction of the experimental results were observed for the CVC pressures of 0.4 and 3 bar at later stage of injection. This was attributed to the higher sensitivity of the results to the input parameters and modelling assumptions for the highest NPR case $(0.4$ bar $)$ and the fluctuations of the poppet valve in the lowest NPR case (3 bar).

The impact of the injector internal geometry was also investigated by comparing the results for the CVC pressure of 1 bar and those using a short version of the injector featuring a part of the hot valve only. It was shown that once the pressure loss inside the injector is accounted for in imposing the inlet boundary conditions of the short injector, a good agreement with the experimental results can be achieved.

The LES results also showed that the external flow consists of three main regions: A "recirculation" zone where mixing is dominant and is present just downstream of the injector tip. This is followed by a "stagnation zone" where 
the axial velocity is almost zero. Downstream of this region is a "far-mixing" zone with a strong mixing occurring outside the jet. The existence of these regions has been reported in previous studies of underexpanded jets. It was also shown that the length of the recirculation zone increases as the CVC pressure decreases. This could be explained using a theory recently developed in the literature for flow behind a bluff body, and highlights the importance of the

CVC pressure on the jet dynamics.

\section{Acknowledgement}

This research was supported by the Australian Research Council (ARC) [LP160100339] and the Ford Motor Company. Mohsen Talei also acknowledges the support of the ARC through the DECRA Fellowship (DE180100416). We also would like to thank Continental for providing the prototype DI CNG injector hardware.

\section{References}

[1] H. Engerer, M. Horn, Natural gas vehicles: An option for europe, Energy Policy 38 (2) (2010) 1017-1029. doi:10.1016/j.enpol.2009.10.054.

[2] Semin, R. A. Bakar, A Technical Review of Compressed Natural Gas as an Alternative Fuel for Internal Combustion Engines (2008). doi:10.3844/ ajeassp.2008.302.311.

[3] M. I. Khan, T. Yasmin, A. Shakoor, Technical overview of compressed natural gas (cng) as a transportation fuel, Renewable and Sustainable Energy Reviews 51 (2015) 785 - 797. doi:10.1016/j.rser.2015.06.053.

[4] G. Kosmadakis, D. Rakopoulos, C. Rakopoulos, Performance and emissions of a methane-fueled spark-ignition engine under consideration of its cyclic variability by using a computational fluid dynamics code, Fuel 258 (2019) 116-154. doi:10.1016/j.fuel.2019.116154 
[5] M. Ferrera, Highly efficient natural gas engines, in: 13th International Conference on Engines and Vehicles, SAE International, Paper No. 201704-0059, (2017). doi:10.4271/2017-24-0059

[6] I. Erfan, I. Chitsaz, M. Ziabasharhagh, A. Hajialimohammadi, B. Fleck, Injection characteristics of gaseous jet injected by a single-hole nozzle direct injector, Fuel 160 (2015) 24-34. doi:10.1016/j.fuel.2015.07.037.

[7] I. Erfan, A. Hajialimohammadi, I. Chitsaz, M. Ziabasharhagh, R. J. Martinuzzi, Influence of chamber pressure on CNG jet characteristics of a multihole high pressure injector, Fuel 197 (2017) 186-193. doi:10.1016/j. fuel.2017.02.018.

[8] L. Bartolucci, R. Scarcelli, T. Wallner, A. Swantek, C. F. Powell, A. Kastengren, D. Duke, Cfd and x-ray analysis of gaseous direct injection from an outward opening injector, in: SAE 2016 World Congress and Exhibition, SAE International, Paper No. 2016-01-0850, (2016). doi: 10.4271/2016-01-0850.

[9] J. Hall, B. Hibberd, S. Streng, M. Bassett, Compressed-natural-gas optimised downsized demonstrator engine, Proceedings of the Institution of Mechanical Engineers, Part D: Journal of Automobile Engineering 232 (1) (2018) 75-89. doi:10.1177/0954407017707552.

[10] Numerical and experimental study of gaseous fuel injection for CNG direct injection, Fuel 140 (2015) 693-700. doi:10.1016/j.fuel.2014.10.018

[11] R. S. Donaldson C., Snedeker, A study of free jet impingement. Part 1. Mean properties of free and impinging jets, Journal of Fluid Mechanics 45 (2) (1971) 281-319. doi:10.1017/S0022112071000053.

[12] A. Hamzehloo, P. Aleiferis, Large eddy simulation of highly turbulent under-expanded hydrogen and methane jets for gaseous-fuelled internal combustion engines, International Journal of Hydrogen Energy 39 (36) (2014) 21275 - 21296. doi:10.1016/j.ijhydene.2014.10.016. 
[13] H. L. Husted, G. Karl, S. Schilling, C. Weber, Direct Injection of CNG for Driving Performance with Low $\mathrm{CO}_{2}$, in: 23rd Aachen Colloquium Automobile and Engine Technology, Aachen, (2014), 829-850.

[14] A. Y. Deshmukh, M. Bode, T. Falkenstein, M. Khosravi, D. van Bebber, M. Klaas, W. Schröder, H. Pitsch, Simulation and Modeling of Direct Gas Injection through Poppet-type Outwardly-opening Injectors in Internal Combustion Engines, Springer Singapore, Singapore, (2019), 65-115. doi:10.1007/978-981-13-3307-1_4

[15] A. B. Swantek, D. J. Duke, A. L. Kastengren, N. Sovis, C. F. Powell, L. Bartolucci, R. Scarcelli, T. Waller, An experimental investigation of gas fuel injection with X-ray radiography, Experimental Thermal and Fluid Science 87 (2017) 15-29. doi:10.1016/j.expthermflusci.2017.04.016.

[16] K. Keskinen, O. Kaario, M. Nuutinen, V. Vuorinen, Z. Künsch, L. O. Liavåg, M. Larmi, Mixture formation in a direct injection gas engine: $\mathrm{Nu}-$ merical study on nozzle type, injection pressure and injection timing effects, Energy 94 (Supplement C) (2016) 542-556. doi:10.1016/j .energy . 2015. 09.121

[17] V. Vuorinen, J. Yu, S. Tirunagari, O. Kaario, M. Larmi, C. Duwig, B. J. Boersma, Large-eddy simulation of highly underexpanded transient gas jets, Physics of Fluids 25 (1) (2013) 1-22. doi:10.1063/1.4772192.

[18] V. Vuorinen, A. Wehrfritz, C. Duwig, B. J. Boersma, Large-eddy simulation on the effect of injection pressure and density on fuel jet mixing in gas engines, Fuel 130 (2014) 241-250. doi:10.1016/j.fuel.2014.04.045.

[19] A. Hamzehloo, P. Aleiferis, Computational Study of Hydrogen Direct Injection for Internal Combustion Engines, SAE international, Paper No. 2013-01-2524, (2013). doi:10.4271/2013-01-2524.

[20] A. Hamzehloo, P. G. Aleiferis, Numerical modelling of transient underexpanded jets under different ambient thermodynamic conditions with 
adaptive mesh refinement, International Journal of Heat and Fluid Flow

61 (Part B) (2016) 711-729. doi:10.1016/j.ijheatfluidflow.2016.07. 015.

[21] M. Baratta, A. E. Catania, F. C. Pesce, CNG Injector Nozzle Design and Flow Prediction, in: ASME Internal Combustion Engine Division Fall Technical Conference, (2010), 795-800. doi:10.1115/ICEF2010-35104.

[22] M. Baratta, A. E. Catania, F. C. Pesce, Multidimensional Modelling of Natural Gas Jet and Mixture Formation in Direct Injection Spark Ignition Engines - Development and Validation of a Virtual Injector Model, Journal of Fluids Engineering 133 (4) (2011) 41304-41314. doi:10.1115/1.4003877

[23] M. Baratta, N. Rapetto, Mixture formation analysis in a direct-injection NG SI engine under different injection timings, Fuel 159 (2015) 675-688. doi:10.1016/j.fuel.2015.07.027.

[24] A. Y. Deshmukh, G. Vishwanathan, M. Bode, H. Pitsch, M. Khosravi, D. van Bebber, Characterization of Hollow Cone Gas Jets in the Context of Direct Gas Injection in Internal Combustion Engines, in: WCX World Congress Experience, SAE International, Paper No. 2018-01-0296, (2018). doi: 10.4271/2018-01-0296.

[25] A. Y. Deshmukh, T. Falkenstein, H. Pitsch, M. Khosravi, D. van Bebber, M. Klaas, W. Schroeder, Numerical Investigation of Direct Gas Injection in an Optical Internal Combustion Engine, in: WCX World Congress Experience, SAE International, Paper No. 2018-01-0171, (2018). doi:10.4271/2018-01-0171.

[26] J. Lacey, M. Meulemans, F. Poursadegh, M. Brear, P. Petersen, U. Kramer, A. Smith, M. Hornby, D. Cosby, P. Czimmek, An optical and numerical characterization of directly injected compressed natural gas jet development at engine-relevant conditions, in: WCX SAE World Congress

\ Experience, SAE International, Paper No. 2019-01-0294, (2019). doi: 10.4271/2019-01-0294. 
[27] M. Hornby, K. Husslein, H. Schüle, C. Heukenroth, W. Klemp, T. Komischke, T. Gerlach, Gas direct injector with reduced leakage, USA Patent No. US9453486B1 (2015).

[28] J. Lacey, F. Poursadegh, M. J. Brear, R. Gordon, P. Petersen, C. Lakey, B. Butcher, S. Ryan, Generalizing the behavior of flash-boiling, plume interaction and spray collapse for multi-hole , direct injection, Fuel 200 (2017) 345-356. doi:10.1016/j.fuel.2017.03.057.

[29] F. Poursadegh, J. S. Lacey, M. J. Brear, R. L. Gordon, On the fuel spray transition to dense fluid mixing at reciprocating engine conditions, Energy \& Fuels 31 (6) (2017) 6445-6454. arXiv:10.1021/acs.energyfuels. 7b00050, doi:10.1021/acs.energyfuels.7b00050.

[30] F. Poursadegh, J. S. Lacey, M. J. Brear, R. L. Gordon, P. Petersen, C. Lakey, B. Butcher, S. Ryan, U. Kramer, On the phase and structural variability of directly injected propane at spark ignition engine conditions, Fuel 222 (2018) 294 - 306. doi:10.1016/j.fuel.2018.02.137.

[31] F. Poursadegh, J. Lacey, M. Brear, R. Gordon, The direct transition of fuel sprays to thedense-fluid mixing regime in the contextof modern compression ignition engines, in: WCX World Congress Experience, SAE International, Paper No. 2018-01-0298, (2018). doi:10.4271/2018-01-0298.

[32] K. J. Richardson, P. Senecal, E. Pomraning, Converge 2.4, Convergent Science, Madison, WI (2017).

[33] R. I. Issa, A. D. Gosman, A. P. Watkins, The computation of compressible and incompressible recirculating flows by a non-iterative implicit scheme,

[ Journal of Computational Physics 62 (1) (1986) 66-82. doi:10.1016/ 0021-9991(86)90100-2.

[34] E. Pomraning, C. J. Rutland, Dynamic One-Equation Nonviscosity LargeEddy Simulation Model, AIAA Journal 40 (4) (2002) 689-701. doi:10. $2514 / 2.1701$ 
[35] Y. Akira, H. Kiyosi, A Statistically-Derived Subgrid-Scale Kinetic Energy Model for the Large-Eddy Simulation of Turbulent Flows, Journal of the Physical Society of Japan 54 (8) (1985) 2834-2839. doi:10.1143/JPSJ. 54.2834

[36] M. Germano, U. Piomelli, P. Moin, W. H. Cabot, A dynamic subgrid-scale eddy viscosity model, Physics of Fluids A: Fluid Dynamics 3 (7) (1991) 1760-1765. doi:10.1063/1.857955

[37] M. Gad-el Hak, The Fluid Mechanics of Microdevices-The Freeman

घ Scholar Lecture, Journal of Fluids Engineering 121 (1) (1999) 5-33. doi: $10.1115 / 1.2822013$

[38] G. S. Settles, Schlieren and Shadowgraph Techniques, Springer, Berlin, Heidelberg, (2001). doi:10.1007/978-3-642-56640-0.

[39] R. Seidel, The upper bound theorem for polytopes: an easy proof of its asymptotic version, Computational Geometry 5 (2) (1995) 115-116. doi: 10.1016/0925-7721(95)00013-Y.

[40] J. L. Lumley, Engines: An Introduction, Cambridge University Press, 1999. URL https://books . google . com . au/books?id=it1BggypJ2oC

[41] S. Crist, D. R. Glass, P. M. Sherman, Study of the highly underexpanded sonic jet., American Institute of Aeronautics and Astronautics 4 (1) (1966) 68-71. doi:10.2514/3.3386.

[42] P. G. Hill, P. Ouellette, Transient turbulent gaseous fuel jets for diesel engines, Journal of Fluids Engineering 121 (1) (1999) 93-101. doi:10. $1115 / 1.2822018$.

[43] A. Hajialimohammadi, D. Edgington-Mitchell, D. Honnery, N. Montazerin, A. Abdullah, M. Agha Mirsalim, Ultra high speed investigation of gaseous jet injected by a single-hole injector and proposing of an analytical method for pressure loss prediction during transient injection, Fuel 184 (2016) 100109. doi:10.1016/j.fuel.2016.06.112. 
[44] Z. A. Kuensch, S. Schlatter, K. Keskinen, T. Hulkkonen, M. Larmi, K. Boulouchos, Experimental investigation on the gas jet behavior for a hollow cone piezoelectric injector, SAE International, Paper No. 2014-012749, (2014). doi:https://doi.org/10.4271/2014-01-2749.

${ }_{625}$ [45] J. C. Massey, I. Langella, N. Swaminathan, A scaling law for the recirculation zone length behind a bluff body in reacting flows, Journal of Fluid Mechanics 875 (2019) 699-724. doi:10.1017/jfm.2019.475. 